Annales Geophysicae (2001) 19: 487-493 (c) European Geophysical Society 2001

\title{
Excitation of transient lobe cell convection and auroral arc at the cusp poleward boundary during a transition of the interplanetary magnetic field from south to north
}

\author{
P. E. Sandholt ${ }^{1}$, C. J. Farrugia ${ }^{2}$, S. W. H. Cowley ${ }^{3}$, M. Lester ${ }^{3}$, and J.-C. Cerisier ${ }^{4}$ \\ ${ }^{1}$ Department of Physics, University of Oslo, P. O. Box 1048, Blindern, N-0316, Norway \\ ${ }^{2}$ Space Science Center, University of New Hampshire, Durham, NH 03824, USA \\ ${ }^{3}$ Department of Physics and Astronomy, University of Leicester, Leicester LE1 7RH, UK \\ ${ }^{4}$ Centre d'Etude des Environnements Terrestre et Planetaires, 4 Avenue de Neptune, 94107 Saint-Maur Cedex, France
}

Received: 21 November 2000 - Revised: 8 March 2001 - Accepted: 15 March 2001

\begin{abstract}
We document the activation of transient polar arcs emanating from the cusp within a 15 min long intermediate phase during the transition from a standard two-cell convection pattern, representative of a strongly southward interplanetary magnetic field (IMF), to a "reverse" two-cell pattern, representative of strongly northward IMF conditions. During the 2-3 min lifetime of the arc, its base in the cusp, appearing as a bright spot, moved eastward toward noon by $\sim 300 \mathrm{~km}$. As the arc moved, it left in its "wake" enhanced cusp precipitation. The polar arc is a tracer of the activation of a lobe convection cell with clockwise vorticity, intruding into the previously established large-scale distorted two-cell pattern, due to an episode of localized lobe reconnection. The lobe cell gives rise to strong flow shear (converging electric field) and an associated sheet of outflowing field-aligned current, which is manifested by the polar arc. The enhanced cusp precipitation represents, in our view, the ionospheric footprint of the lobe reconnection process.
\end{abstract}

Key words. Magnetospheric physics (auroral phenomena; magnetopause, cusp, and boundary layers; plasma convection)

\section{Introduction}

Ground observations of the optical aurora and ionospheric ion drift in the cusp region have the distinct advantages of continuity of coverage and sufficient temporal-spatial sensitivity to monitor signatures of solar wind/magnetosphere/ ionosphere interaction mechanisms. Such observations have provided important information on the temporal variability of the magnetopause magnetic reconnection processes taking place poleward and equatorward of the cusp during northward and southward interplanetary magnetic field (IMF) con-

Correspondence to: P. E. Sandholt

(p.e.sandholt@fys.uio.no) ditions, respectively (Sandholt et al., 1998a; Sandholt and Farrugia, 1999). Of particular interest here is the dynamic transition state of the cusp ionosphere excited by rapid northward turnings of the IMF (Øieroset et al., 1997; Sandholt et al., 1998b; Lockwood and Moen, 1999; Milan et al., 2000). The different phases of the dynamics of the cusp aurora during a 40 min interval of strongly northward IMF, after a rapid northward turning, have been described in two recent studies (Sandholt et al., 1999, 2000). The interval was characterized by a sequence of intensifications and poleward expansions of the cusp poleward boundary, accompanied by activations of reverse (equatorward) convection.

Here we document an important additional, smaller-scale aspect of the dynamics of the cusp-polar cap boundary taking place in the early phase following the northward turning of the IMF. A careful inspection of the green line aurora reveals that the cusp intensifications described above are accompanied by short-lived ( $2-3 \mathrm{~min})$ polar arcs emanating from bright spots forming at the cusp poleward boundary. The event we study shows the activation of a green line polar arc that moved across the local magnetic meridian (1100 MLT) from west to east during its $\sim 2-3$ min duration in the phase of transition from standard merging cell $\left(B_{z} \ll 0\right)$ to reverse two-cell $\left(B_{z} \gg 0\right)$ convection. The close association of the optical phenomenon (polar arcs emanating from the cusp band, containing strong green line and weaker red line emissions) and bursts of equatorward convection, as observed in the same area of space by ground-based radar, led us to conclude that the arc results from magnetosphere-ionosphere coupling (sheets of field-aligned current) activated by bursts of lobe reconnection. The auroral/convection event was initiated approximately $5 \mathrm{~min}$ after the northward IMF arrived at the subsolar magnetopause. This estimate is based on the identification of the ground magnetic impulse event (MIE) relating to the solar wind dynamic pressure pulse which accompanied the IMF transition from south to north. 


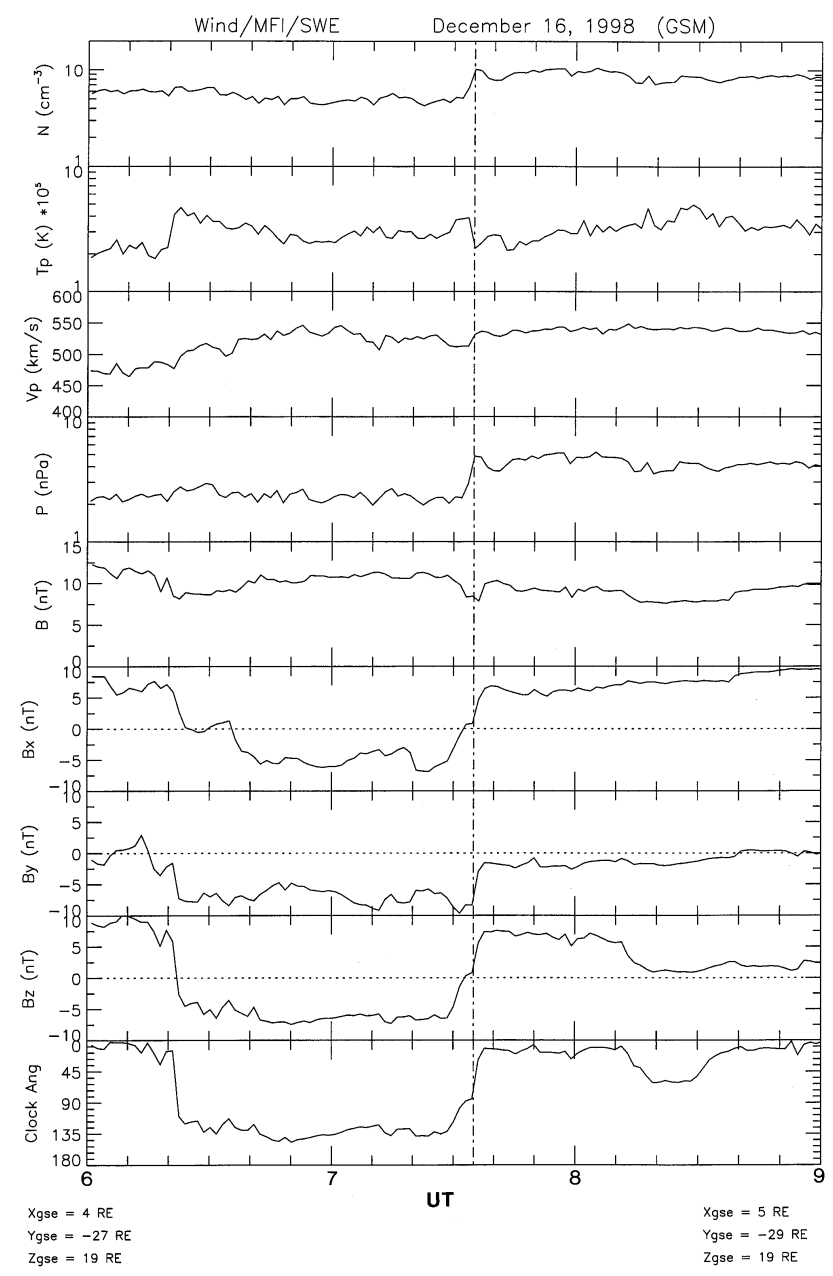

Fig. 1. Wind plasma and magnetic field observations from the Magnetic Field Investigation and Solar Wind Experiment instruments. From top to bottom are shown the proton density, temperature, bulk speed, dynamic pressure, the total field, its GSM $x, y$, and $z$ components, and the IMF clock angle. The IMF northward turning centered at 0735 UT is marked by vertical dash-dot line.

\section{Observations}

Figure 1 shows IMF observations obtained from the spacecraft Wind for the interval 0600-0900 UT on 16 December 1998. During this time, the spacecraft was in the solar wind on the dawnside of the magnetosphere at $(5,-28,19)$ $R_{E}$ (GSE coordinates). We note the transition from strongly southward to strongly northward IMF orientation recorded by Wind during the interval 0730-0738 UT. This northward turning, marked by a vertical dash-dot line in the figure, was followed by a 35 min interval of strongly northward IMF, when the IMF clock angle, i.e. the polar angle in the GSM $Y Z$ plane, was $\leq 15^{\circ}$. In this period, $B_{x}$ was positive, and $B_{y}$ slightly negative.

Figure 2 shows meridian scanning photometer (MSP) observations at (a) $630.0 \mathrm{~nm}$ and (b) $557.7 \mathrm{~nm}$, from Ny Ålesund, Svalbard ( $76^{\circ}$ MLAT), during the interval 0720-0800 UT on 16 December 1998. We note that the aurora was ini-

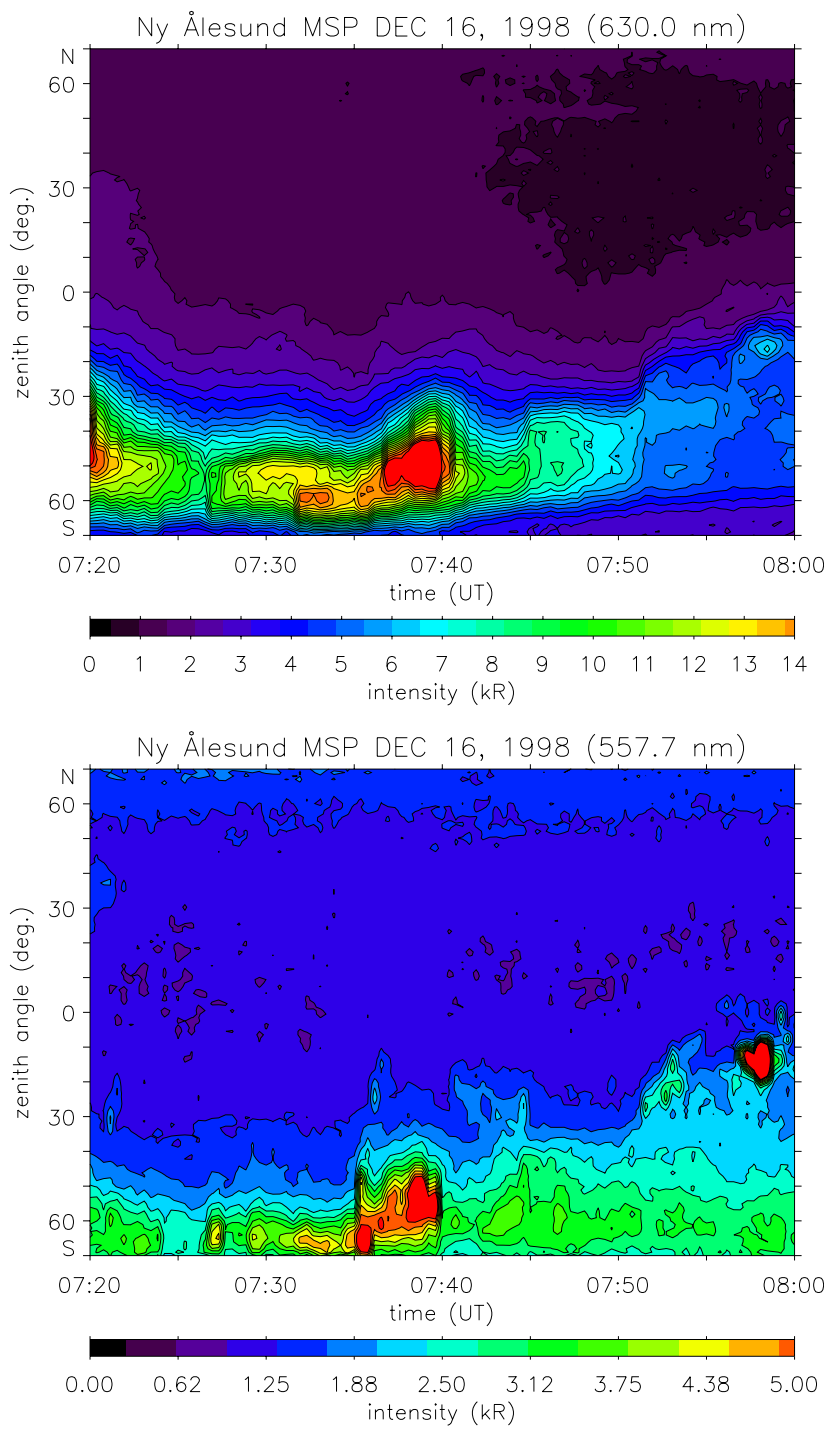

Fig. 2. Color-coded meridian scanning photometer (MSP) observations of line of sight auroral intensities at (a) $630.0 \mathrm{~nm}$ and (b) $557.7 \mathrm{~nm}$ as a function of zenith angle. North is up. The observations were recorded from Ny Ålesund $\left(76^{\circ}\right.$ MLAT) during the interval 0720-0800 UT on 16 December 1998.

tially displaced well south of Ny Ålesund, consistent with the strongly southward IMF orientation before $\sim 0725$ UT. Strong auroral intensifications occurred at 0731-32 and 0735 UT, before a stepwise poleward expansion and weakening of the cusp aurora took place during 0740-0800 UT. These are all effects attributed to the northward turning of the IMF, first affecting the cusp aurora at $\sim 0730$ UT (Sandholt et al., 2000).

In this study, we shall concentrate on the brightest auroral event which followed the northward turning of the IMF, observed along the MSP meridian during the interval 07350740 UT. The green line panel of Fig. 2 shows a short-lived excursion toward the zenith, emanating from the cusp poleward boundary, at 0735-36 UT. As we shall see below, this is a transient polar arc emanating from the cusp region, which 


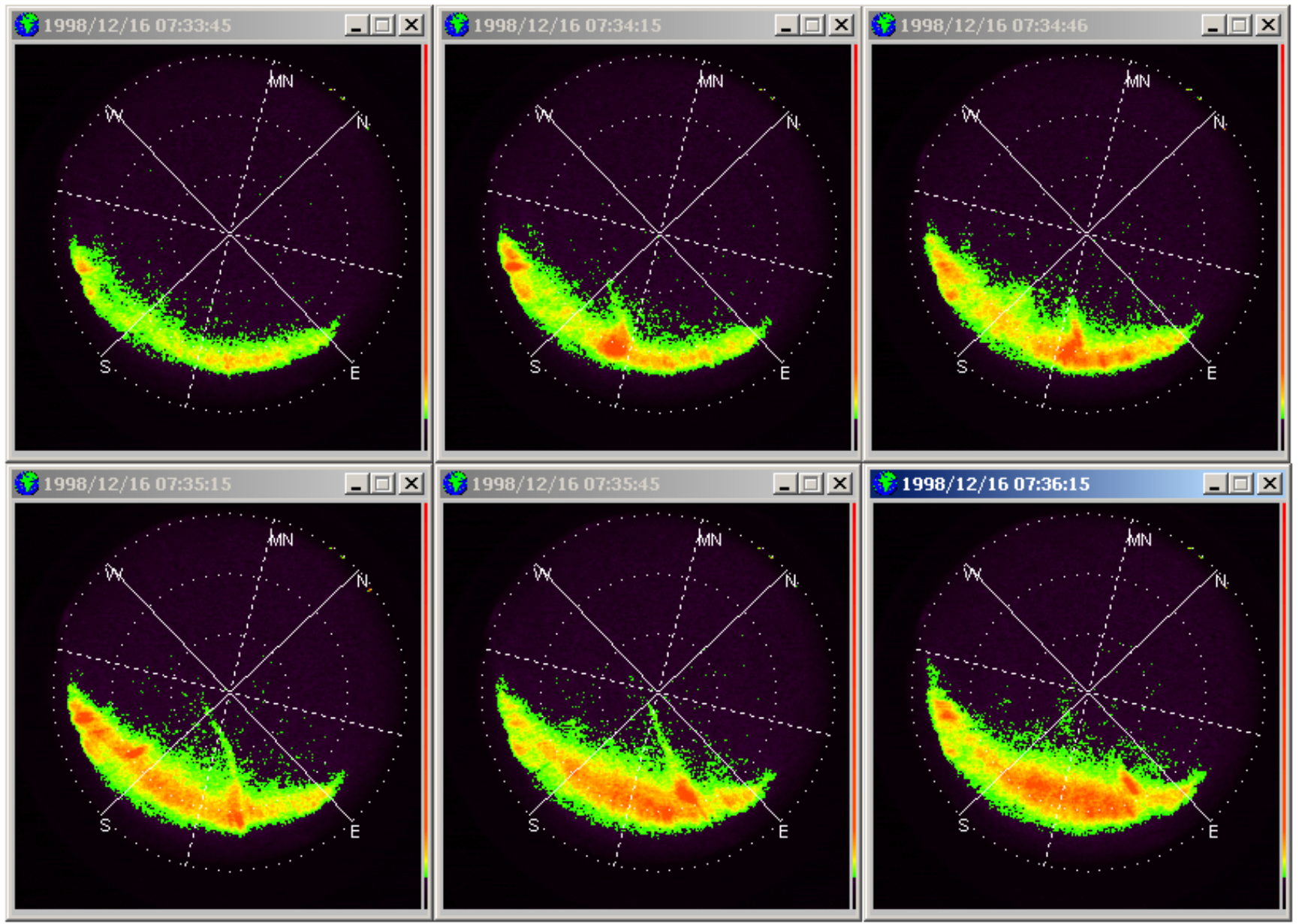

Fig. 3. All-sky auroral images at 557.7 nm taken at Ny Ålesund at the times 0733:45, 0734:15, 0743:46, 0735:15, 0735:45, and 0736:15 UT. The reference system is zenith angle (dashed circles representing $30^{\circ}, 60^{\circ}$, and $90^{\circ}$ ) and azimuth angle. The magnetic meridian through Ny Ålesund is marked by dashed line (MN).

crossed the MSP meridian during its eastward motion in the 1000-1100 MLT sector.

Figure 3 shows a sequence of six all-sky images at 557.7 $\mathrm{nm}$ for the interval 0733-0736 UT, covering the initial phase of the second auroral brightening event shown in Fig. 2. The initial brightening appears as a bright spot located slightly west of the MSP meridian in the second (0734:15 UT) image. A careful inspection reveals a faint polar arc emanating from the bright spot. The next four images, representing the interval 0734:45-0736:15 UT, show the eastward motion of both the bright spot and the polar arc. The bright spot crossed the MSP meridian at 0734:45 UT. The arc manifests itself as a transient form extending poleward (towards zenith) from the intensified cusp emission, which can also be seen in the lower panel of Fig. 2. The polar arc lasted for approximately 2 min (0734-0736 UT). The arc intensity is observed to decrease with distance away from the bright spot at the cusp poleward boundary. The transient arc marks the initial phase of the event of enhanced cusp emission, which lasted until 0940 UT.

A schematic summary of the observation geometry in magnetic latitude/magnetic local time (MLAT/MLT) coordinates, with the cusp poleward boundary (solid curved line), the bright spot (circle) and the polar arc at 0734 and 0736 UT, is shown in Fig. 4. The fields of view of the optical instruments and beam 9 of the CUTLASS Finland radar are also marked in the figure.

Figure 5 shows line-of-sight ion drift velocities obtained by beam 9 of the CUTLASS Finland HF radar during the interval 0720-0750 UT. The radar was operating in a nonstandard mode during the interval, hence, the variable time resolution of the data (for a full description of the mode, see Thorolfsson et al., 2000). The field of view of beam 9 is indicated in Fig. 4. Onsets of auroral brightening events are marked by vertical lines. An arrow marks the second vertical line in the figure, representing 0735 UT, which is the time when the polar arc has just crossed the MSP scanning meridian during its eastward motion in the 1000-1100 MLT sector. At this time (0735-0736 UT), a transition from northward ("away flow"; red) to equatorward ("toward flow"; green) is observed within $70^{\circ}-75^{\circ}$ MLAT, in beam 9. This state lasted until 0738 UT, when a return to northward occurred. A new 


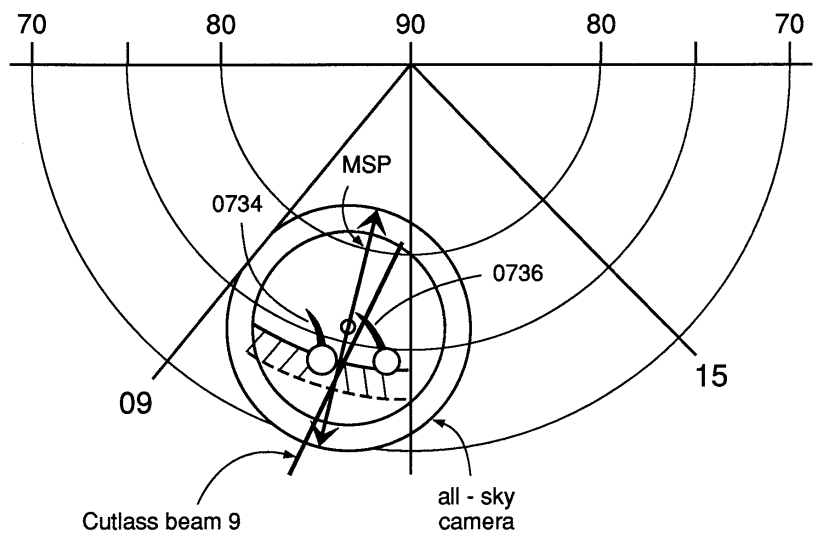

Fig. 4. Observation geometry with the poleward boundary of the cusp emission band (solid curved line) and the polar arc emanating from a bright spot (marked by small circle) in the vicinity of the cusp poleward boundary for 0734 and 0736 UT. Fields of view of the optical instruments (MSP and all-sky camera for both 630.0 and $557.7 \mathrm{~nm}$ emissions) at Ny Ålesund and beam 9 of the CUTLASS Finland HF radar have been marked.

event of strong equatorward flow occurred at 0742-43 UT. Here we focus on the $0735-0738$ UT event.

A spatial plot of the line-of-sight ion drift pattern in the area around Svalbard at 0736 UT is shown in the lower panel of Fig. 5. Ion drift vectors have been superposed using a beam-swinging algorithm given by Villain et al. (1987) and Ruohoniemi et al. (1989). The spatial plot of line-of-sight velocities are reproduced at higher resolution in Fig. 6. Velocities are color-coded according to the scale to the right. Blue is toward (equatorward) and red is away (antisunward) from the radar. A schematic convection pattern consistent with the observed line-of-sight velocities is indicated. It consists of the remnant merging (M) cell convection in the north and the transient lobe (L) cell intruding during the auroral brightening event. The latter is marked by the hatched area. A region of expected upward field aligned current associated with a flow reversal is indicated by small dotted circles. The radar observations are consistent with relatively strong eastward flow poleward of the cusp, in the northeastern part of the backscatter region. The flow in the vicinity of the cusp aurora is westward, with a significant equatorward component in the 1000-1100 MLT sector.

Figure 7 shows $X$ component magnetograms from IMAGE chain stations on Svalbard (NAL-BJN) and at Troms $\varnothing$ (TRO) for the interval 0720-0750 UT. A magnetic impulse event (MIE) at $\sim 0727$ UT is marked by a vertical dashed line. This event reflects the solar wind dynamic pressure pulse associated with the IMF discontinuity/northward turning recorded by Wind at 0735 UT (see Fig. 1). It is most clearly seen at the lower-latitude stations, particularly at TRO (Troms $\varnothing$ ). The associated auroral signature at 0727 UT is seen in Fig. 2b. The relationship between the magnetic/convection and auroral signatures of MIEs has been documented by Luhr et al. (1996).

The MIE at 0727 UT marks the approximate time of ar-

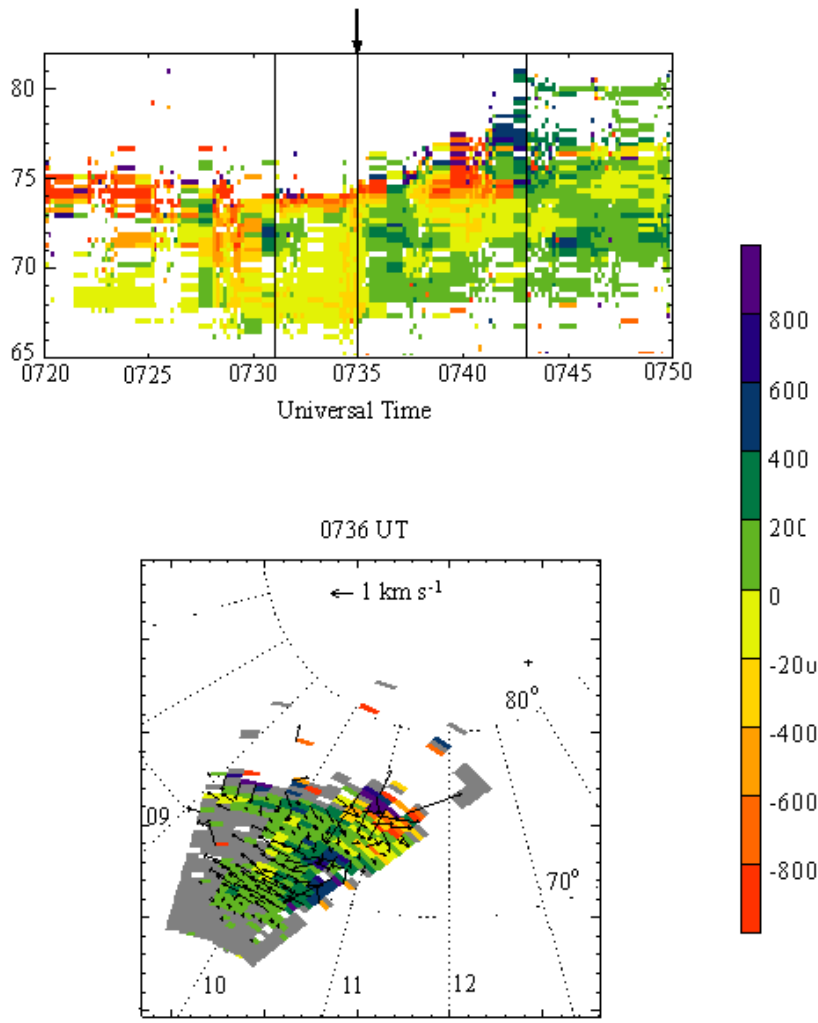

Fig. 5. Upper panel: Line-of-sight ion drift velocities obtained by beam 9 of the CUTLASS Finland HF radar during the interval 0720-0750 UT. Velocities are color-coded according to the scale to the right. Blue/dark green is toward (equatorward) and red is away (antisunward) from the radar. Onsets of auroral brightening and/or poleward expansion events are marked by vertical lines. Arrow marks the onset of the event studied in this paper. Lower panel: Spatial plot of line-of-sight ion velocities within the total field of view of the CUTLASS radar for 0736 UT plotted in an MLT/MLAT reference system. Ion drift vectors obtained by a beam-swinging technique are superposed.

rival of the northward IMF orientation at the subsolar magnetopause. The interval of the transient auroral arc at the cusp poleward boundary is marked by vertical dash-dot lines at 0733 and 0736 UT. From this information, we may infer that this auroral event was initiated approximately $5 \mathrm{~min}$ after the arrival of the northward IMF orientation at the subsolar magnetopause. The positive $X$ component deflection observed at stations HOP-BJN $\left(71.3^{\circ}-72.9^{\circ}\right.$ CGMLAT), centered at $0735 \mathrm{UT}$, is consistent with the westward convection in the region of the enhanced cusp precipitation, indicated in Fig. 6, based on the radar observations.

\section{Discussion}

The phenomenon we focus on is the activation of a transient polar arc emanating from a bright spot at the cusp poleward boundary, which occurred in the transition phase when the IMF rotated from strongly south to north. The IMF vector 


\section{SUPERDARN PARAMETER PLOT HANKASALMI: vel}

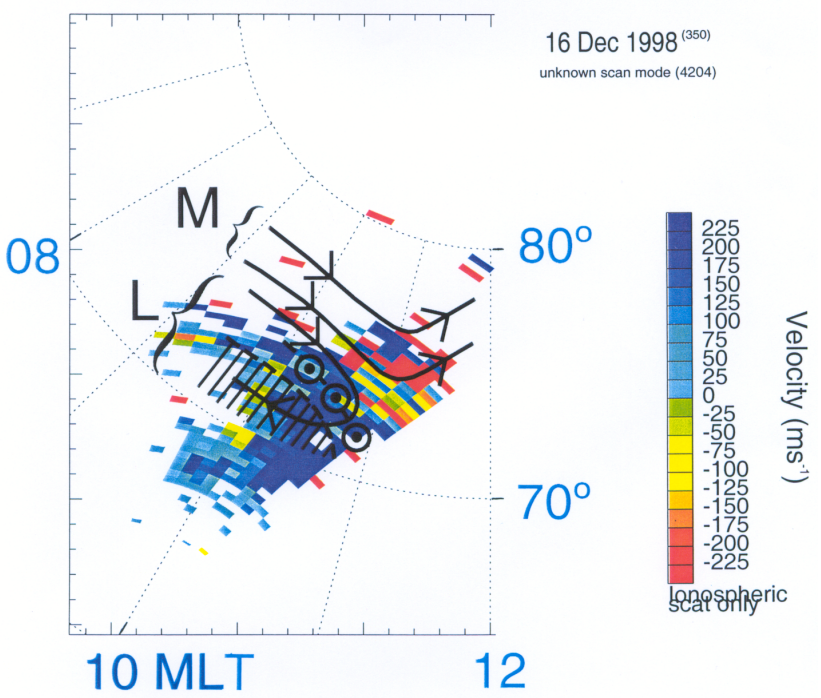

Fig. 6. Spatial plot of line-of-sight ion velocities within the total field of view of the CUTLASS radar for 0736 UT plotted in an MLT/MLAT reference system. The $70^{\circ}$ and $80^{\circ}$ MLAT circles, as well as the MLT meridians from within 0700-1200, are marked. A convection pattern with merging $(\mathrm{M})$ and lobe $(\mathrm{L})$ cells is indicated by arrowed curves. Hatched area marks the cusp auroral brightening. Small dotted circles mark the location of upward field aligned current/transient polar arc (see also Fig. 8).

rotated from $(-5,-7,-5)$ to $(6,-2,7)$ in less than $10 \mathrm{~min}$. The gross features of the ionospheric response to this IMF transition, which may be divided in three phases, are indicated in Fig. 5 of Sandholt et al. (2000). The aurora and flow pattern prior to the northward turn of the IMF is that of a distorted two-cell pattern with a significant eastward component in the cusp region, consistent with the negative IMF $B_{y}$ component. The aurora typically shows a sharp equatorward boundary from which transient poleward moving auroral forms (PMAFs) are emanating (Thorolfsson et al., 2000). This is the aurora we, in previous work, refer to as the type 1 cusp region aurora (Sandholt et al., 1998a; Sandholt and Farrugia, 1999).

Phase 1 (0727-0730 UT) is the first ionospheric signature which can be associated with the northward turning. This is a magnetic impulse event (MIE) observed within a wide range of latitudes equatorwards from the cusp (Fig. 7). This impulse event is accompanied by a moderate auroral brightening. The event is possibly triggered by the rapid enhancement of solar wind density (dynamic pressure) which accompanied the actual IMF directional discontinuity. Phase $2(0730$ 0745 UT) represents the first $15 \mathrm{~min}$ after the initial response and is the one we concentrate on. It consists of two discrete episodes of auroral intensification, each of which is accompanied by short-lived ( $\sim 3 \mathrm{~min})$, localized events of equatorward convection. These events are both followed by the reforming of the standard distorted two-cell pattern, which is

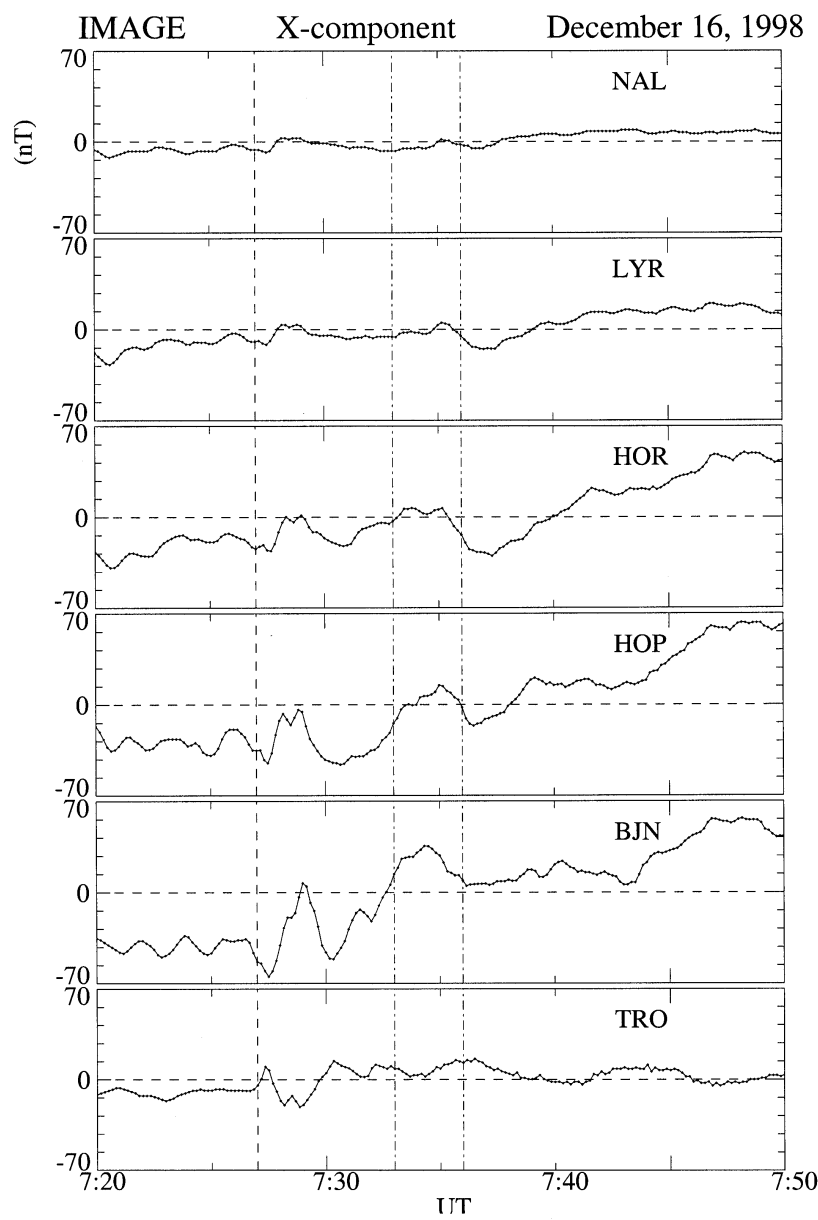

Fig. 7. $X$ component magnetograms from IMAGE chain stations on Svalbard and at Troms $\varnothing$ (TRO) for the interval 0720-0750 UT. The station coordinates are: NAL $\left(76.1^{\circ}\right.$ CGMLAT), LYR $\left(75.1^{\circ}\right.$ CGMLAT), HOR (74.0 $0^{\circ}$ CGMLAT), HOP (72.9 ${ }^{\circ}$ CGMLAT), BJN (71.3 ${ }^{\circ}$ CGMLAT), TRO (66.5 ${ }^{\circ}$ CGMLAT). Magnetic impulse event at 0727 UT is marked by vertical dashed line, while the auroral arc/convection event we focus on is marked by vertical dash-dot lines at 0733 and $0736 \mathrm{UT}$.

reminiscent of the previous interval of strongly southward IMF. Thus, phase 2 consists of a mixture of ionospheric signatures attributed to reconnection processes taking place both poleward and equatorward of the cusp. Phase 3, which occupies the next $25 \mathrm{~min}(0745-0810 \mathrm{UT})$, is entirely regulated by the strongly northward IMF orientation. It is characterized by a sequence of poleward expansions and latitudinal broadenings of the cusp emission band and events of reverse convection (Figs. 2 and 5). In this case, the cusp aurora, which we call type 2 , is characterized by a sharp poleward boundary.

The connection between the cusp dynamics and the excitation of the transient polar arc in phase 2, is indicated schematically in Fig. 8. It adds an important element to the previously reported observations, having important implications on the magnetosphere-ionosphere coupling during the phase of transition from low-latitude to high-latitude reconnection. 


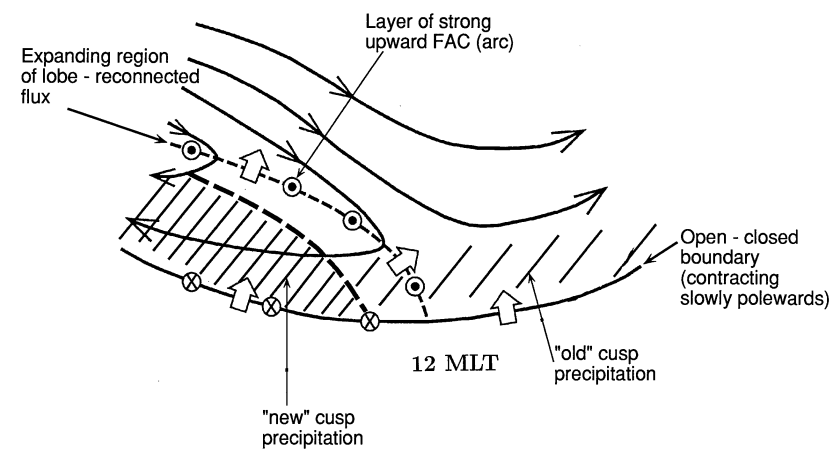

Fig. 8. Schematic of convection and field-aligned current (FAC) geometry in the $\sim 1000-1200$ MLT cusp region, illustrating the intrusion of transient lobe convection cell and the polar arc emanating from the eastern boundary of the new enhanced cusp emission. The latter is marked by the hatched area on the left side of the figure. North is up and west is to the left. The polar arc (upward FAC) is located near the boundary between fast eastward flows in the poleward region, driven by the previous interval of southward IMF, and the the much slower flows which have an equatorward component, which is associated with lobe reconnection.

Polar cap arcs are generally associated with flow lines of polar plasma flow and gradients of plasma flow during northward IMF orientation (Burke et al., 1982; Gussenhoven, 1982; Hardy et al., 1982). Polar arcs are, furthermore, associated with a pair of meso-scale field-aligned currents; the outflowing component is carried by sheets of incoming electrons, and an associated ionospheric flow channel (Chiu, 1989; Weiss et al., 1993).

In the present case, the transient arc and the associated channel of equatorward (sunward) convection are observed to intrude into a large-scale convection pattern established during the previous southward IMF interval (decays totally after $15 \mathrm{~min}$ of northward IMF by the end of phase 2). A region of strong flow shear develops during the activation and expansion of the lobe cell, between the eastward flow at higher latitudes, driven by continuing $B_{y}$ field tension, and semi-stagnant plasma just joined to northward IMF and westward flowing magnetosheath. The sense of the shear is such that it requires an upward field-aligned current, as illustrated in Fig. 8. One result is the polar arc emanating from the cusp poleward boundary. Furthermore, we suggest that the eastward motion of the polar arc is related to the evolution of the IMF-magnetosphere interconnection geometry during the event onset (expansion of the lobe reconnection site), taking into account the strongly northward $B_{z}(7 \mathrm{nT})$ and small negative $B_{y}$ /positive $B_{x}$ condition. The band of new enhanced cusp precipitation, marked in Fig. 8, represents, in our view, the ionospheric footprint of the lobe reconnection process.

Acknowledgements. This work is partially supported by DARA grant 50 OC 89110 and by NASA grant NAG 5-2834. CUTLASS Operations are supported by PPARC grant PPA/R/R/1997/00256. The work of Stan Cowley and Mark Lester is supported by grant PPA/G/O/1999/00181. The IMAGE magnetometer data used in this paper were collected as a German-Finnish-Polish-Norwegian project conducted by the Technical University of Braunschweig and the Finnish Meteorological Institute. The auroral observation program on Svalbard is supported by the Norwegian Research Council and the Norwegian Polar Research Institute. Special thanks are due to Bjørn Lybekk and Espen Trondsen for technical assistance with the optical data.

The Editor in Chief thanks H. Opgenoorth for his help in evaluating this paper.

\section{References}

Burke, W. J., Gussenhoven, M. S., Kelley, M. C., Hardy, D. A., and Rich, F. J., Electric and magnetic field characteristics of discrete arcs in the polar cap, J. Geophys. Res., 87, 2431, 1982.

Chiu, Y. T., Formation of polar cap arcs, Geophys. Res. Lett., 16, 743, 1989.

Gussenhoven, M. S., Extremely high latitude auroras, J. Geophys. Res., 87, 2401, 1982.

Hardy, D. A., Burke, W. J., and Gussenhoven, M. S., Dmsp optical and electron measurements in the vicinity of polar cap arcs, J. Geophys. Res., 87, 2413, 1982.

Lockwood, M. and Moen, J., Reconfiguration and closure of lobe flux by reconnection during northward IMF: Possible evidence for signatures in the cusp/cleft auroral emissions, Ann. Geophysicae, 17, 996, 1999.

Luhr, H., Lockwood, M., Sandholt, P. E., Hansen, T., and Moretto, T., Multi-instrument ground-based observations of a travelling convection vortices event, Ann. Geophysicae, 14, 162, 1996.

Milan, S., Lester, M., Cowley, S. W. H., and Brittnacher, M., Dayside convection and auroral morphology during an interval of northward interplanetary magnetic field, Ann. Geophysicae, 18, 436, 2000.

Øieroset, M., Sandholt, P. E., Denig, W. F., and Cowley, S. W. H., Northward interplanetary magnetic field cusp aurora and highlatitude magnetopause reconnection, J. Geophys. Res., 102, 11349, 1997.

Ruohoniemi, J. M., Greenwald, R. A., Baker, K. B., Villain, J. P., Hanuise, C., and Kelly, J., Mapping high-latitude plasma convection with coherent HF radars, J. Geophys. Res., 94, 13463, 1989.

Sandholt, P. E. and Farrugia, C. J., On the dynamic cusp aurora and IMF $B_{y}$, J. Geophys. Res., 104, 12461, 1999.

Sandholt, P. E., Farrugia, C. J., and Cowley, S. W. H., Pulsating cusp aurora for northward IMF, J. Geophys. Res., 103, 26507, 1998a.

Sandholt, P. E., Farrugia, C. J., Moen, J., Noraberg, Ø., Lybekk, B., Sten, T., and Hansen, T., A classification of dayside auroral forms and activities as a function of IMF orientation, J. Geophys. Res., 103, 23325, 1998b.

Sandholt, P. E., Farrugia, C. J., Cowley, S. W. H., Denig, W. F., Lester, M., and Lybekk, B., Capture of magnetosheath plasma by the magnetosphere during northward IMF, Geophys. Res. Lett, 26, 2833, 1999.

Sandholt, P. E. et al., Dynamic cusp aurora and associated pulsed reverse convection during northward IMF, J. Geophys. Res., 105, 12869, 2000.

Thorolfsson, A., Cerisier, J.-C., Lockwood, M., Sandholt, P. E., Senior, C., and Lester, M., Simultaneous optical and radar signatures of poleward moving auroral forms, Ann. Geophysicae, 18 (9), 1054, 2000.

Villain, J. P., Greenwald, R. A., Baker, K. B., and Ruohoniemi, 
J. M., HF radar observations of $\mathrm{E}$ region plasma irregularities produced by oblique plasma streaming, J. Geophys. Res., 92, 12,327, 1987.

Weiss, L. A., Weber, E. J., Reiff, P. H., Sharber, J. R., Winningham, J. D., Primdahl, F., Mikkelsen, I. S., Seifring, C., and Wescott,
E. M., Convection and electrodynamic signatures in the vicinity of a Sun-aligned Arc: Results from the Polar Acceleration Regions and Convection Study (Polar Arcs), in Auroral Plasma Dynamics, Ed. R. L. Lysak, vol. 80 of Geophysical Monograph Series, pp. 69-80, 1993. 